Revista Iberoamericana, Vol. LXXVIII, Núm. 241, Octubre-Diciembre 2012, 895-911

\title{
DESPLAZAMIENTOS Y CAMBIOS DE SIGNO: LA REESCRITURA DE EL JUGUETE RABIOSO (1926), DE ROBERTO ARLT, EN SI YO MUERO PRIMERO (1991), DE SUSANA SILVESTRE Y LA NUEVA $R A B I A$ (2008), DE MARCELO ECKHARDT
}

\author{
POR \\ KaRina Elizabeth VázQueZ \\ Missouri Western State University
}

Uno de los rasgos sobresalientes de la narrativa argentina de los últimos quince años es el retorno de la estética realista. Esta tendencia comprende textos cuya verosimilitud no se asimila ni al pacto mimético profesado por los escritores realistas del treinta, ni al realismo comprometido, de influencia sartreana, de los setenta. ${ }^{1}$ Durante la década del ochenta, la escritura cifrada, basada en la alusión y la alegoría, con la que escritoras y escritores respondieron a la censura y represión sistemática de la última dictadura militar (1976-1983), zanjó el problema del imperativo político en la literatura mediante el rechazo de "lo real". No obstante, hacia mediados de la década del noventa, éste resurge en el discurso literario como consecuencia, fundamentalmente, de dos factores: el agotamiento del modelo de escritura basado en el desvío hiperliterario, que desde comienzos de la década enfrentó el interés por la revisión de la historia argentina (Avellaneda, "Recordando"; Dalmaroni); y la crisis social creada por la aplicación de las políticas neoliberales acordadas en el Consenso de Washington (1995), que impusieron un acelerado proceso de precarización laboral. Al amparo de políticas excluyentes, altas tasas de desempleo, subempleo y trabajo informal condujeron a una crisis cuyo ápice fue el estallido social de diciembre de 2001. Este contexto propició una crisis de representaciones sociales y políticas que ha dado como resultado una reconfiguración del lugar de enunciación del escritor.

El quiebre con la estética autorreferencial que había predominado desde fines de los setenta es resultado entonces de un reacomodamiento ideológico-cultural que reconfigura el lugar de enunciación del escritor, la relación entre texto y lectura, y replantea variables del campo literario tales como el trabajo con los géneros discursivos

\footnotetext{
1 Entre los primeros se encuentran los escritores de filiación socialista y anarquista reunidos en Boedo, tales como Alberto Ghiraldo, Elías Castelnuovo, Leónidas Barletta, Bernardo González Arrilli; y entre los segundos se reconoce a los integrantes de Contorno (David Viñas, Noé Jitrik), y a escritores como Germán Rozenmacher y Andrés Rivera.
} 
(Bakhtin). En gran parte de la narrativa argentina escrita a partir de los noventa, "lo real” no es el resultado de abstracciones ideológicas. Por el contrario, estos textos rechazan la aplicación de manuales monológicos de ideología (Drucaroff) y formulan un “decir lo político” que cuestiona las subjetividades de género y clase. El tratamiento de temas como el silencio cómplice frente al terrorismo de estado, la memoria y la impunidad, el lugar del escritor y la identidad de los trabajadores queda formulado mediante una tensión entre la doxa de la estética alusiva y la heterodoxia en la que lo individual y lo social se vuelven mutuamente representativos.

Entre mediados y fines de los noventa, entonces, el campo literario ve emerger textos cuya adscripción al verosímil recurre principalmente al distanciamiento crítico por parte del lector. Esta "fórmula" (Jakobson) innegablemente tiene por modelo el "realismo crítico” de Roberto Arlt (Jitrik 102). En disonancia con las convenciones de los escritores del treinta, el realismo arltiano se caracteriza por llevar a la superficie del texto las contradicciones ideológicas sobre las que hacia la década del veinte se había edificado un sistema cultural dador de prestigio. Sus textos presentan figuraciones que desestabilizan el lugar de emplazamiento del lector, y lo conducen a un "distanciamiento" que, sin caer en la desidentificación, propicia la reflexión crítica (Capdevila 226). Es precisamente este verosímil crítico el rasgo que reaparece en los “nuevos realismos” a partir de mediados de los noventa, generando la posibilidad de nombrar lo innombrable en un contexto social marcado por la desorientación y la incertidumbre.

Algunas de las características más notorias de esta reanudada presencia del realismo en la narrativa argentina son el tratamiento de la última dictadura militar (1976-1983) y el trabajo. El primero introduce la perspectiva de los victimarios y los cómplices, y el segundo reinscribe tema laboral mediante la inversión del topos de la mujer obrera. ${ }^{2}$ Por ejemplo, las novelas Villa (1995) de Luis Gusmán, Dos veces junio (2001) de Martín Kohan y El secreto y las voces (2002) de Carlos Gamerro, formulan la participación indirecta de la sociedad en el plan represivo dictatorial. Estas novelas rompen con una narrativa que dice lo político por medio de la alusión, la autorreferencialidad y la hiperliterariedad (Avellaneda, “Recordando” 126), y cuyo paradigma máximo es Respiración artificial (1980) de Ricardo Piglia. Los universos narrados irrumpen en la semiotización del vacío a la que condujo la extrapolación del paradigma alusivo durante los ochenta y comienzos de los noventa, y surgen textos cuyo verosímil comparte zonas con el mundo extraliterario del lector, invitándolo no ya a descifrar, sino a reflexionar sobre el presente. Esto es fuertemente notorio en novelas como Vivir afuera (1998) y

\footnotetext{
2 Para un análisis de la representación literaria de las trabajadoras industriales a lo largo de la literatura argentina del siglo xx, ver "Trabajo y literatura: el topos de la mujer obrera en la narrativa argentina del siglo XX” en: http://www.elinterpretador.net/34KarinaElizabethVazquez-ElToposDeLaMujerObrera. html.

Revista Iberoamericana, Vol. LXXVIII, Núm. 241, Octubre-Diciembre 2012, 895-911
ISSN 0034-9631 (Impreso)
} 
En otro orden de cosas (2001) de Rodolfo Fogwill, que plantean la conexión entre ese pasado dictatorial y las transformaciones culturales y laborales de los ochenta y noventa. Más recientemente, las novelas El trabajo (2007) de Aníbal Jarkowski y Combi (2008) de Angela Pradelli proponen reflexionar sobre el deterioro de las condiciones de trabajo y el desempleo desde la perspectiva del presente.

El retorno del realismo parece así estar relacionado directamente con una revisión de los últimos treinta años de la historia argentina, en la cual la desigualdad social y la crisis laboral ocupan un espacio temático medular. Ejemplo de esto es la novela Boca de lobo (2002) de Sergio Chejfec, que subvierte la equivalencia entre obrera y prostituta figurada tanto por el realismo del treinta, como por la escritura comprometida de los sesenta. A partir de la presentación del antagonismo entre el mundo del trabajo y la cultura, este texto le propone al lector reflexionar sobre la construcción recíproca de las identidades de clase y de género a lo largo de la historia argentina. La novela muestra entonces que realismo y trabajo están unidos en un tipo de escritura que repiensa la relación entre el pasado y el presente a partir de la crítica de los supuestos ideológicos fundantes en la cultura argentina y en las identidades de clase y género.

Este ensayo se propone estudiar ambos aspectos -retorno del realismo y presencia temática del trabajo-, en los dos extremos temporales de la serie mencionada anteriormente, mediante el análisis de la reescritura de El juguete rabioso (1926) de Roberto Arlt, en las novelas Si yo muero primero (1991) de Susana Silvestre y La nueva rabia (2008) de Marcelo Eckhardt. El vínculo entre estas tres novelas se produce tanto a nivel formal -las tres proponen un texto que asume la forma del Bildungsroman-, como temático -en las tres el trabajo es el núcleo semántico principal-. Al respecto, los sistemas de connotaciones (Barthes) desplegados en las novelas de Silvestre y Eckhardt, revelan rupturas y continuidades tanto con las significaciones textuales arltianas, como con las premisas culturales articuladoras del campo crítico y literario argentino. En efecto, en las situaciones por las que transitan los personajes de estas novelas, se transponen contradicciones ideológicas subyacentes en el sistema cultural dador de prestigio que son allanadas por la forma en que éstos mismos resuelven su presente hacia el final de las novelas.

La publicación de la novela de Silvestre tiene lugar cerca del final del período de predominio de la escritura alusiva surgido como respuesta al imperativo realista de los sesenta y al silencio impuesto por la última dictadura militar. La significación de este texto reside en la formulación de un orden de representación que al fraguar realidad social e historia con experiencia individual muestra desde una perspectiva de género las fisuras del modelo cultural. Por otro lado, si bien la novela de Eckhardt reproduce lugares comunes del campo literario, al mismo tiempo ficcionaliza antagonismos de orden político que introducen en el sistema de connotaciones textuales un conjunto de tensiones que invitan a repensar las premisas ideológicas del campo cultural y literario argentino.

\footnotetext{
Revista Iberoamericana, Vol. LXXVIII, Núm. 241, Octubre-Diciembre 2012, 895-911 ISSN 0034-9631 (Impreso)

ISSN 2154-4794 (Electrónico)
} 
Si yo muero primero de Silvestre, no se presenta a sí misma como una reescritura de El juguete rabioso; no obstante, el tratamiento del núcleo semántico “trabajo” sugiere una lectura desplazada del texto de Arlt. Por el contrario, La nueva rabia de Eckhard, anuncia ya en su título la continuidad con la historia de Silvio Astier, el personaje arltiano. Tanto en Si yo muero primero como en La nueva rabia la representación del "trabajo" pone en evidencia la persistencia, dentro y fuera del campo literario, del antagonismo entre trabajo y cultura criticado por Arlt en su novela. Los rasgos distintivos del orden de representación de ambos textos proponen, por un lado, una mirada femenina sobre el mundo laboral que irrumpe en el predominio de voces masculinas al respecto, y por el otro, la continuación crítica de un orden simbólico que privilegia la noción letrada de la cultura por sobre la experiencia de trabajo. ${ }^{3}$ Tomando en cuenta estas particularidades, este ensayo estudia en ambas novelas los siguientes aspectos: a) la significación de las variaciones semánticas del trabajo respecto de la novela de Arlt, y b) su posicionamiento dentro del Bildungsroman.

La representación arltiana del trabajo desestabilizó el horizonte de expectativas del lector de la década del treinta mediante dos mecanismos: la inversión de núcleos semánticos (Jitrik 73-75), y la desfamiliarización (Avellaneda, “Clase media” 63). El primero deja entrever en el texto el sustrato ideológico del cual surge, mientras que el segundo rompe los automatismos de lectura del público lector de clase media. ${ }^{4} \mathrm{Al}$ ensamblar las representaciones de la educación formal con las del trabajo asalariado, El juguete rabioso genera un sistema de connotaciones textuales que pone de manifiesto la conexión entre el antagonismo trabajo vs. cultura y las desigualdades sociales.

Para comprender la significación de la inversión semántica del trabajo en la novela deArlt es preciso identificar primeramente los discursos culturales, ideológicos y políticos que estructuraron el imaginario social de la época. Hacia la década del veinte, tanto para el socialismo como para el anarquismo, la educación ocupaba un papel central en la integración social del individuo. Para los socialistas, la educación era el motor de la conciencia cívica y la emancipación de los trabajadores, por lo que se constituía en una condición previa, separada y antagónica de la experiencia laboral. Por el contrario, a pesar de su posición ambigua frente a la noción ilustrada de la cultura (Suriano), los

3 La distinción entre trabajo físico y trabajo manual no es producto de la posesión de facultades específicas, sino de un papel que la sociedad atribuye a un individuo cuyo saber especializado tiene la función de apoyar un determinado modo de ejercer el poder. El trabajo puramente físico o intelectual no existe como tal, pues la tarea intelectual se halla presente también en la labor manual; es decir, cualquier trabajo físico y mecánico involucra un mínimo de calificación. El lugar social no deriva de un valor inherente e inmanente, sino de las relaciones en las que se estas tareas se hallan insertas (Gramsci 31).

4 Un lector que reproduce el mito del ascenso social individual y conoce la amenaza que significa el pasaje al mundo asalariado. Los personajes de Arlt " [...] son en este sentido portadores de grandes mitos que subliman los fantasmas de ese argentino de las capas medias, como el mito de la fuga desde la ciudad rumbo al campo puro" (Avellaneda, “Clase media” 644).

\footnotetext{
(3) Revista Iberoamericana, Vol. LXXVIII, Núm. 241, Octubre-Diciembre 2012, 895-911 ISSN 0034-9631 (Impreso) ISSN 2154-4794 (Electrónico)
} 
anarquistas proponían una contigüidad entre educación y trabajo que los marginaba de la política educativa oficial, ámbito en el que el socialismo participó activamente. ${ }^{5}$

En la década del treinta, la ciudad de Buenos Aires era una Babel edificada sobre las expectativas de ascenso social y las experiencias de fracaso. A la movilidad individual gestada hacia fines del siglo diecinueve, se sumaba ahora la propiciada por la escolarización masiva, las profesiones liberales y la homogeneización del mercado de trabajo urbano. Con la expansión de los medios de comunicación, las bibliotecas populares y el transporte, tuvieron lugar nuevos patrones de consumo cultural y de uso del tiempo libre. La educación, el comercio y el trabajo estatal fueron los medios de ascenso social de los sectores medios de la Capital Federal. La educación pública y la difusión de la lectura a través de las publicaciones semanales y de las bibliotecas populares -en su mayoría asociadas a la militancia socialista-, trazaron modelos de identidad de género (Sarlo) en el imaginario colectivo acordes a los perfiles del ciudadano, al mismo tiempo que funcionaron como herramientas disciplinarias y diferenciadoras de género y clase. ${ }^{6}$ A medida que la industrialización imprimía en los sectores asalariados una identidad más homogénea, en las clases medias el trabajo dejó de ser una variable identitaria. La jornada laboral se convirtió en "las ocho horas que sirven para” llevar a cabo actividades “cultas” o educativas, fundamentalmente en la esfera privada; percepción ésta que demuestra la internalización de la noción abstracta del tiempo de trabajo. La formación de un sector trabajador más homogéneo, si bien representó el progreso de las luchas laborales, también materializó una amenaza para la identidad de los sectores medios, que percibían el mundo asalariado como la imposición de jerarquías y la limitación del tiempo libre.

La sociedad desde y sobre la cual escribe Arlt, ve en la educación formal y en el hábito de la lectura las herramientas esenciales para la valoración del individuo. El juguete rabioso cuestiona esta percepción por medio de la inversión semántica del trabajo. Silvio Astier narra su proceso de integración social dando cuenta de su pasaje de estudiante a asalariado. A instancias de su madre, se emplea como aprendiz de librero

5 El socialismo ilustrado enfatizó las prácticas culturales por fuera del ámbito laboral, acentuando el carácter escolar del uso del tiempo. Tuvo un rol opositor-complementario en la política educativa oficial, y su postura contribuyó a que ésta persiguiera y eliminara propuestas alternativas como la anarquista, que apoyó programas autogestivos y alternativos (Barrancos 9). No obstante, las prácticas culturales anarquistas también se apoyaban en una noción letrada de la cultura, aunque sus expresiones cubrieron un espectro más heterogéneo y difícil de clasificar (Suriano 113, 118, 129, 130).

6 El modelo de cultura socialista se proponía orientar a los que no podían acceder al sistema educativo formal a causa del trabajo. De acuerdo a la "política de los libros” socialista “[...] Todos los días [...] numerosos lectores, obreros en su mayoría, leen cariñosamente, buscando buen solaz; unos conocimiento, otros, según las aficiones y necesidades espirituales [...] Nadie habla, sólo se lee [...]” (Barrancos 101). Esta propuesta demuestra la voluntad de orientar la lectura con fines pedagógicos e instructivos, colocando a la cultura en el lugar del control social y político.

Revista Iberoamericana, Vol. LXXVIII, Núm. 241, Octubre-Diciembre 2012, $895-911$
ISSN 0034-9631 (Impreso) 
porque la adquisición de un oficio le garantizaba el sustento familiar y le prometía la posibilidad de una futura independencia económica. Pero para él, el ingreso al mundo laboral significa el alejamiento de los amigos del barrio y sobre todo, implica la pérdida del tiempo para la lectura de novelas de aventuras. ${ }^{7}$ Los distintos trabajos por los que transita denotan la situación de explotación; de ahí que ninguno de éstos le proporcione dinero y entrenamiento. El trabajo aparece entonces como un robo invertido ${ }^{8}$ que lleva a Silvio a pensar en el delito como un acto de restitución. Su traición al rengo, quien le propone robar en la casa de un ingeniero, no contradice este razonamiento para dar lugar a un aprendizaje moral; por el contrario, demuestra la aceptación de una integración social desigual. El trabajo asalariado, que embrutece y desvaloriza, es su única opción en una sociedad cuyo modelo de movilidad social ascendente comienza a mostrar limitaciones (Sábato y Romero 241).

Los núcleos semánticos ‘trabajo’ y ‘educación’ adquieren entonces una valoración inversa al sentido que tienen en el campo semántico extraliterario. Tiene lugar un extrañamiento que pone en evidencia un sistema de connotación textual disonante respecto del horizonte de expectativas del lector. La presentación del trabajo bajo la forma de robo invertido, y de la educación como un bien inaccesible, desnaturalizan las instituciones y los valores establecidos en la sociedad argentina del treinta (Avellaneda, “Queremos” 2). El texto de Arlt muestra algo que de otro modo es imposible de percibir: la percepción del trabajo como un tiempo muerto no es inmanente y está determinada por las condiciones laborales y la valoración social del trabajo frente a los hábitos de lectura y educación impuestos por la cultura hegemónica. Mediante la inversión de los núcleos semánticos y la desfamiliarización, el texto revela que las pautas culturales hegemónicas promueven una ideología de desigualdad social. Por lo tanto, el robo es presentado como la alternativa que sirve para reparar el tiempo perdido por la desigualdad de origen y otorgar un reconocimiento que el trabajo asalariado no provee. El texto “iguala prácticas ilícitas e inmorales con prácticas aceptadas como normales, con lo que éstas quedan investidas de la condenación ética y política que le corresponden a las primeras" (Avellaneda, "Clase” 64), y muestra que la disparidad entre el trabajo y la cultura es una norma socialmente instituida.

7 El énfasis en la educación como medio para la independencia económica se sostiene en la idea de que la educación enriquece al individuo permitiéndole ser conciente de su poder. La lectura es vista como "a means of making connection with other ideas and knowledge over space and time. Its application altered the user's relationship with the immediate and local discourses sustained by oral modes of communication. Reading and writing promoted motionless mobility” (Vincent 99).

8 Para Jitrik, “[...] aún desde una perspectiva representativo realista, El juguete rabioso saca a la superficie elementos de su ideología poniéndolos por eso en crisis, lo que permite suponer que asume las contradicciones en las que se basa; más aún, sobre esa tensión principal se constituiría su sistema productivo de significación, o sea, lo que hay que buscar y determinar” (72).

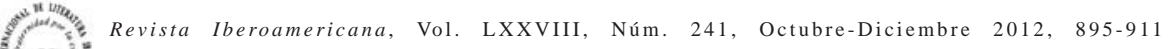
ISSN 0034-9631 (Impreso) $\quad$ ISSN 2154-4794 (Electrónico)
} 
Si yo muero primero, de Susana Silvestre, reproduce esta percepción del trabajo como una esfera antagónica y excluyente del ámbito cultural. La novela presenta los conflictos de Liliana Soledad Rao, una joven de catorce años, perteneciente a una familia de clase trabajadora de la Pcia. de Buenos Aires, que hacia mediados de la década del sesenta abandona la escuela e ingresa al mercado laboral para ayudar a la economía familiar. Su resentimiento es una mezcla de la aceptación del pasado familiar obrero, sobre todo el de su madre y del rechazo de su condición de asalariada. Durante dos años transita por distintos trabajos en la Capital Federal, desde dependienta en un comercio mayorista, hasta secretaria en una empresa. Este último está marcado por dos hechos importantes: la relación con Fondebrider (su jefe), mucho mayor que ella y casado, y el ingreso a la escuela secundaria nocturna. El proceso de aprendizaje culmina con dos hechos determinantes para el futuro del personaje: la obtención del título secundario y la llegada a su vida de otras mujeres, en este caso, militantes de los sesenta. Ambos acontecimientos hacen posible la perspectiva de un nuevo empleo y el final de la relación con su jefe.

Al igual que en la novela de Arlt, el ingreso de Liliana al mercado laboral responde a las necesidades materiales de la familia, entre las cuales se incluye también la educación de los hermanos menores (Si yo 19). El trabajo interrumpe su deseo de estudiar, pero sobre todo, obstaculiza el camino hacia una profesión que pondría fin a su condición de asalariada $(15,64)$. Como Silvio Astier, el personaje de Silvestre padece las limitaciones de la movilidad social ascendente y enfrenta con pesar su ingreso al mundo laboral. El recuerdo detallado de los distintos trabajos fabriles por los que pasó su madre (21), empuja a Liliana a evitar el trabajo industrial mediante la obtención del título secundario. Su recorrido laboral se asemeja bastante al de Silvio Astier: de ayudante-aprendiz (87), a operaria en una fábrica (87), y por último, a secretaria en una empresa constructora (89). Pero, a diferencia de Silvio, Liliana logra ocupar ese tiempo muerto con la lectura, hecho que remarca la percepción de un antagonismo entre trabajo no calificado o semicalificado (111), y la vocación profesional y el hábito de la lectura.

En la novela de Arlt, el trabajo adolescente de Silvio pone de relieve que la falta de un saber específico condena al empleado a la alienación del automatismo y a la dependencia. En la novela de Silvestre, el trabajo femenino remarca la relación entre falta de calificación laboral y valoración social del empleo. En efecto, a pesar de que la apreciación del lugar de la mujer en la producción industrial, y en el mundo laboral en general, cambió notablemente a lo largo del siglo xx, la novela de Silvestre hace visible el carácter interviniente de la variable de género en la reproducción social del antagonismo entre trabajo y cultura/educación formal. Las características y la frecuencia de la representación literaria de la obrera a lo largo del siglo veinte han respondido a la interacción de factores de diverso orden, los cuales han reproducido los imperativos de la movilidad social ascendente anidados en la experiencia de los sectores medios.

\footnotetext{
Revista Iberoamericana, Vol. LXXVIII, Núm. 241, Octubre-Diciembre 2012, 895-911 ISSN 0034-9631 (Impreso)

ISSN 2154-4794 (Electrónico)
} 
Tanto desde las perspectivas de izquierda, como desde del conservadurismo católico, los autores realistas del treinta compartieron propósitos pedagógicos comunes que figuraron a la fábrica como un espacio pernicioso para la mujer. A pesar de la dignificación del trabajo femenino durante los dos primeros gobiernos peronistas (1946-1955), hacia las décadas del setenta (fecha de la historia narrada) y del noventa (fecha de publicación), el trabajo asalariado femenino (sobre todo el doméstico y el fabril) continúa estigmatizado frente a las profesiones liberales y a la enseñanza. Los cambios producidos por la industrialización de los cincuenta y las leyes laborales promovidas en ese período, implicaron cambios significativos en los sectores trabajadores. No obstante, a pesar de que hacia la década del sesenta la ocupación femenina en la industria siguió aventajado al empleo en el comercio y los servicios, la fábrica continuó portando una valoración menos digna (degradante) que las profesiones de maestra o enfermera (Lobato 67).

Puede decirse entonces que la novela de Silvestre presenta el trabajo dentro de un sistema de connotaciones textuales que reproduce el imaginario social criticado en El juguete rabioso. En tanto hija de la clase trabajadora, Liliana reproduce una visión hegemónica que hace invisible el trabajo femenino, pero que además niega el capital social y cultural de los asalariados. No obstante, al presentar la perspectiva femenina, el texto despliega un sistema de equivalencias semánticas en el que el trabajo de la mujer es equiparado al robo y la explotación, y la educación formal al poder masculino. En este sentido, la novela de Silvestre no cambia el signo de la representación del trabajo, sino que lo expande y complejiza. El recorrido laboral de Liliana pone en evidencia que, independientemente de la calificación laboral, la flexibilidad laboral femenina reproduce los papeles tradicionales de la mujer. La particularidad de la novela de Silvestre es mostrar la correlación entre la construcción de las diferencias de género y clase y las identidades de género y clase, asumiendo un destino biológico las primeras, y un devenir histórico las segundas (Secombe).

En La nueva rabia, de Marcelo Eckhardt, la vinculación con el texto arltiano es más directa que en la novela de Silvestre; el personaje-narrador le anuncia al lector que se encuentra frente a las memorias de Silvio Astier, las cuales recogen su paso por la Patagonia. La indicación sobre los cambios de signo parecería sugerirle al lector que las connotaciones de este texto son iguales a las de El juguete rabioso. El nombre Nicolás Radek reemplaza a Silvio Astier, el trabajo industrial sustituye al empleo en el comercio, y la esposa suplanta la presencia femenina materna. Pero si en el texto arltiano la oposición entre trabajo y cultura produce un sistema de significaciones disonante para el lector, ${ }^{9}$ en el texto de Eckhardt este antagonismo genera un sistema de connotaciones

9 Varios desarrollan, desde la fenomenología (Iser) al estructuralismo (Barthes), distintos conceptos y esquemas explicativos de la interacción entre texto y lector. Partiendo del uso que Jakobson hace de los términos langue y parole. Jauss, por su parte, entiende que la recepción de un texto, es decir, la comprensión de su "significado", presupone un contexto intersubjetivo de experiencia. Iser propone un

\footnotetext{
Sevista Iberoamericana, Vol. LXXVIII, Núm. 241, Octubre-Diciembre 2012, 895-911 ISSN 0034-9631 (Impreso) ISSN 2154-4794 (Electrónico)
} 
menos inquietante. El robo es suplantado por el trabajo en la refinería de YPF, el mundo prostibulario es sustituido por la vida familiar, el club de ladrones por el sindicato, y la pasión por la lectura es renovada por la escritura y el encuentro con Borges (Eckhardt 57). Esta cadena de sustituciones reafirma la oposición entre trabajo y cultura que es revelada en el texto arltiano por la inversión del núcleo semántico trabajo.

La inclusión de Radek en "El club de los soviéticos” refiere al anarcosindicalismo y, de ese modo, al tránsito por caminos alternativos a los predominantes en el ámbito urbano porteño de las décadas del treinta y del cuarenta. Sin embargo, el tono que asumen las alusiones al trabajo, la escritura, la tradición literaria, las mujeres y el peronismo señala que en realidad los cambios de signo presentes en el texto no implican ninguna indagación crítica de la oposición entre trabajo y cultura. Por el contrario, para Nicolás Radek, trabajar en YPF no significa un robo invertido, sino un simple intercambio de dinero por el trabajo realizado (19); el cual, finalmente, le permite suplir la demanda familiar: mantener a la madre y pagar la educación de su hermana, que se dedicará a la literatura.

En el sistema de connotaciones arltiano, el trabajo en tanto medio de integración social está marcado por la explotación. En la novela de Eckhardt, por el contrario, el trabajo es definitivamente un medio para la integración armoniosa. Nicolás Radek ha internalizado la noción abstracta del tiempo de trabajo como tiempo que permite el intercambio equivalente de entidades cualitativamente distintas (Marx 86). En efecto, la constante búsqueda de la felicidad y las acusaciones dirigidas al Astrólogo (personaje místico de Los lanzallamas) (Eckhardt 31), indican que Radek llega a ocupar un lugar social alejado de los conflictos y las contradicciones del pasado. Hacer el trabajo que le gusta (107), es decir, realizarse a través de la actividad laboral, ${ }^{10}$ y relacionarse con una mujer como Sara, bella, amante, compañera, trabajadora y madre, indican que Radek ha logrado aniquilar el resentimiento que recorre tanto a Silvio Astier como a otros personajes artianos.

En esta novela aparecen otras marcas de integración que se oponen al texto de Arlt. En primer lugar, el encuentro con Borges en Comodoro Rivadavia, en el capítulo "El poeta de la dignidad", que no sólo ajusta al personaje de Eckhardt con la "buena escritura”, sino que reconciliaría a la escritura de Arlt con los preceptos de la tradición literaria argentina. Segundo, el perdón del rengo, que libera al personaje tanto de la culpa como del resentimiento, permitiéndole buscar en paz la felicidad (44). En tercer lugar, el rechazo del peronismo (125, 166, 167), expresado en el encuentro con Perón en

tipo de análisis basado en la idea de que la "significación” del texto no se encuentra en el texto mismo, sino que es resultado de la interacción de este con el lector (Jauss 10).

10 Una noción ésta del trabajo "no alienante" que es frecuente en algunas corrientes socialistas de fines del siglo xIx y principios del xx, para las que el trabajo, como noción o concepto general, estaba más asociado con la actividad del artesano del siglo XvII que con la del obrero de planta (Armstrong 17).

Revista Iberoamericana, Vol. LXXVIII, Núm. 241, Octubre-Diciembre 2012, 895-911
ISSN 0034-9631 (Impreso) 
el capítulo “Un militar del pueblo”, que ratifica la aceptación de las normas culturales hegemónicas. Por último, la homologación de las condiciones de trabajo en la década del treinta con las del presente, signadas por los efectos de las políticas neoliberales de los noventa, que revalidaría la vigencia de ese sistema cultural. Aunque el texto denuncia el abuso laboral propiciado por la Ley Nacional de Empleo 24.013, que en la década del noventa dejó sin efecto los derechos laborales obtenidos en la década del cincuenta, deja al soslayo el papel del peronismo en el ámbito laboral de ese período y posteriormente, al ratificar de forma acrítica las premisas de la izquierda ilustrada que contraponen trabajo y cultura. Por lo tanto, se puede afirmar que, al igual que Si yo muero primero, de Silvestre, la novela de Eckhardt obtura en el texto la visualización crítica del antagonismo entre cultura y trabajo, crucial en El juguete rabioso y refuerza la percepción de que la cultura asegura mayor dignidad que el trabajo.

En términos del género literario de estas novelas, todas ellas se adscriben al Bildungsroman. Este tipo de relato describe en primera persona un proceso de aprendizaje individual que conduce a la madurez y la integración social (Bakhtin). El ejemplo tradicional dentro del canon literario argentino es Don Segundo Sombra (1926), de Ricardo Güiraldes, donde el personaje toma conciencia de su lugar en la escala social gracias a la ayuda del maestro. El Bildungsroman presenta entonces un carácter normativo que solidifica o cuestiona determinados aspectos dentro del programa ideológico de formación del ciudadano (Diego). Narrar tiene como fin pedagógico mostrar en el plano de la ficción que la integración es resultado de la internalización de la norma social. Sin embargo, hay personajes que no aceptan la imposición de la jerarquía o se incorporan a ella por medio de actitudes condenables como la traición y el robo. Tal es el caso del personaje de El juguete rabioso, que muestra la heterodoxia del género al presentar el resentimiento como experiencia fundante. En efecto, esta novela presenta una carga ideológica, moral y cultural surgida del contexto de "relaciones dialógicas" presentadas en el texto, que le imprime un sentido de "justicia social” que va más allá del devenir del personaje (Kushigian 19), y es distintivo del Bildungsroman hispanoamericano. En oposición al Bildungsroman europeo surgido en el siglo XIX, que simboliza una noción de la modernidad basada en la intranquilidad y la convulsión del período de la juventud (Moretti 4-5), el Bildungsroman hispanoamericano sintetiza una experiencia en la que "the individual's subjective goals of love, honor, and ambition do not always lead, as Hegel concluded, to the protagonist's getting the girl and somekind of job, marrying, and becoming a philistine just like others” (Kushigian 19). En este sentido, la novela de Arlt representa una especie de anti-Bildungsroman en el que la integración social del individuo es el resultado del resentimiento de clase y del rechazo de la norma a través de acciones punibles.

La novela de Silvestre también es un texto que narra el enfrentamiento con las distintas instancias represivas de la sociedad, y al mismo tiempo da cuenta de "[...] un proceso de deconstrucción del relato de aprendizaje tal como está escrito en el

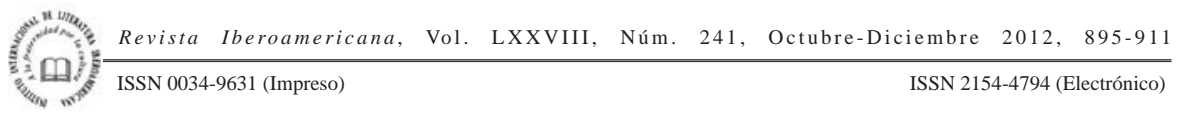


canon masculino” (Avellaneda, “Construyendo” 228). Igual que el texto arltiano, confirma la diversidad de rasgos que acepta el género; por un lado, no cuenta con la figura del maestro y, por el otro, presenta un personaje cuyo aprendizaje no muestra un carácter acomodaticio, sino que evidencia el desarrollo de una “autoconciencia crítica” (Fontela $)^{11}$ y dialógica. Como en el caso de Silvio Astier, en esta novela el desarrollo de la autoconciencia se produce alrededor de los conflictos que genera el ingreso del personaje al mercado laboral y su consecuente salida del sistema educativo formal. Pero el texto de Silvestre presenta una voz crítica inédita y escasamente explorada: la representación femenina del trabajo, cuyo desvío respecto del sistema de connotaciones arltiano pone de manifiesto la correlación entre las variables de género y clase y la construcción de las identidades sociales.

En Si yo muero primero, de Silvestre, la retrospección que une pasado y presente del personaje exhibe el carácter normativo que asume la resolución de los conflictos entre el "yo" y el mundo por medio del aprendizaje. Sin embargo, el tratamiento del núcleo semántico “trabajo”, especialmente su antagonismo respecto a la "educación formal”, exhibe un “desarrollo de la autoconciencia” que va más allá del carácter acomodaticio del personaje. La finalización de una relación amorosa desigual y de un trabajo expoliador representan en el personaje el desarrollo de una mirada crítica sobre la realidad que le ha tocado vivir. En este sentido, Liliana Soledad Rao y Silvio Astier tienen en común una experiencia laboral que los coloca en un ángulo crítico respecto del orden social instituido. Sin embargo, como se observó en el análisis del núcleo semántico “trabajo” en Si yo muero primero, el personaje reproduce el papel funcional del antagonismo educación/cultura vs. trabajo dentro del sistema de inequidad social. Tanto Liliana Rao, como Silvio Astier presentan discrepancias que se transponen en el sistema de connotaciones de cada texto. Por ejemplo, si bien los dos personajes tienen un recorrido laboral marcado por la explotación y la dependencia, Liliana llega a establecer una relación afectiva en ese ámbito, mientras que Silvio no lo logra. Por otro lado, el paso por los distintos empleos, y sobre todo la relación con Fondebrider, le ha facilitado a Liliana la posibilidad de terminar la escuela secundaria, algo que a Silvio tampoco le es posible. Para ambos personajes, el título secundario está directamente relacionado con un cambio dentro de la escala social, por lo que el aprendizaje de Liliana refrenda el papel de la educación formal en la valoración de los individuos. Por el contrario, las condiciones laborales no le permiten a Silvio el acceso a la escuela y su penosa situación se resuelve por el robo y la traición, que lo conducen nuevamente al mundo asalariado.

11 María de los Angeles Fontela traza las características del género aplicando la dialéctica hegeliana del amo y el esclavo y establece una oposición entre novela de carácter y novela de acontecimiento. La primera “[...] se vertebra narrativamente en el eje de la conflictividad yo-Mundo. El protagonista, actor y receptor de su propio proceso formativo, gestado en esa conflictividad, obtiene por autoconciencia, un conocimiento de sí mismo, o lo que es lo mismo, su propia identidad” (52).

Revista Iberoamericana, Vol. LXXVIII, Núm. 241, Octubre-Diciembre 2012, 895-911
ISSN 2154-4794 (Electrónico) 
En efecto, el encuentro de Liliana con mujeres militantes de los setenta, y su acceso a la prensa de esa época, materializan independencia intelectual, material y de género; pero, al mismo tiempo parecen indicar una continuidad lógica entre movilidad social ascendente, independencia de género y cultura letrada. Estas diferencias respecto de la relación entre trabajo y educación en ambos personajes ponen de manifiesto que la riqueza del texto de Silvestre no reside en su identificación como anti-Bildungsroman, sino en la presentación, desde una perspectiva femenina, de la persistencia de las prerrogativas culturales criticadas por Arlt.

En el caso de La nueva rabia, de Marcelo Eckhardt, sucede algo diferente. En El juguete rabioso queda claro que, por un lado, la escuela ocupa en el imaginario social un espacio separado y antagónico al trabajo, pero al mismo tiempo, como medio de movilidad social presenta limitaciones. Sin embargo, a pesar de que en novela de Eckhardt el mundo laboral es el ámbito que le permite a Nicolás Radek reconciliar conocimiento y aspiraciones sociales (14), la separación entre el trabajo y la vida cultural permanece incuestionable. En el texto aún prevalece la percepción de las instituciones políticas, sindicales y laborales como espacios vacíos de instrucción y pedagogía respecto de la formación escolar. El aprendizaje sintetizado en las memorias de Radek prioriza el espacio de la educación formal por sobre el ámbito laboral, y por sobre todo, exhibe una integración social basada en la reconciliación individual con la sociedad. Si el texto arltiano se caracteriza por ser un anti-Bildungsroman, el texto de Eckhard propone todo lo contrario: un relato de aprendizaje que ratifica los parámetros de encauzamiento social, y que transpone al plano ficcional debates ideológicos del campo literario argentino. A pesar de reunir el tono crítico y dialógico presentes en el Bildungsroman hispanoamericano, la novela de Eckhardt resuena con la búsqueda de significado en el futuro, característica del Bildungsroman europeo que transpone la experiencia de la modernidad.

En los capítulos titulados “La risa vengadora” y "El poeta de la dignidad”, Eckhardt plantea dos aspectos centrales en la historia literaria argentina del siglo xx. En el primero, se trata de un supuesto que se ha mantenido hasta el presente en el campo de la crítica literaria: la supuesta mala escritura de Roberto Arlt. De El juguete rabioso, Elías Castelnuovo -escritor realista y miembro del grupo de Boedo durante la década del veinte-, opina en 1969: "El libro de cuentos [...] ofrecía innumerables fallas de diversa índole, empezando por la ortografía, siguiendo por la redacción y terminando por la unidad y coherencia del texto. Le señalé hasta doce palabras de una suntuosidad insultante, mal colocadas por añadidura, cuyo significado no supo determinar” (Pezzoni 173). ${ }^{12}$ En efecto, al reconocer la "mala literatura" que ha escrito en el pasado (51),

${ }_{12}$ Según Castelnuovo, pobreza gramatical y falta de cohesión textual evidencian poca destreza en el manejo del lenguaje, e impiden a los personajes y al submundo arltiano alcanzar una representación realista acabada (23).

ISSN 2154-4794 (Electrónico)
ISSN 0034-9631 (Impreso) 
Radek, el personaje de La nueva rabia, sugiere un acuerdo con este postulado. Por otra parte, en el capítulo "El poeta de la dignidad", su encuentro con Borges ficcionaliza una inmediatez dentro del campo literario entre el realismo arltiano y el simbolismo teórico borgeano. El reconocimiento de Borges como el “maestro" (Eckhardt 59), es una resolución en el plano de la ficción de las disonancias entre los sistemas de connotación figurados por Arlt y por Borges. Tal encuentro tiene un efecto atenuador de las enormes diferencias entre ambos escritores respecto del sistema cultural y político del cual surgieron sus textos, pero además con él la novela de Eckhardt busca ajustar la "mala escritura” de Arlt a los parámetros de la tradición literaria.

Otro aspecto importante en la representación del aprendizaje del personaje de Eckhardt, es la resolución de un conjunto de tensiones ideológicas presentes en los textos de Arlt Los siete locos (1929) y Los lanzallamas (1931), mediante la transposición al plano ficcional de conflictos en el orden de lo ideológico y político. En el capítulo titulado "Un militar del pueblo", el encuentro entre Radek y Perón deja en claro la distancia ideológica entre el tono anárquico de Arlt, manifestado en estas dos novelas, y el populismo autoritario de Perón (Eckhardt 127). En este encuentro se ponen en un mismo plano dos procesos contemporáneos de marcada trascendencia tanto en el campo literario, como en el político: la revaloración de Roberto Arlt y el debateideológico-cultural en torno al peronismo a comienzos de los sesenta. La novela de Eckhardt busca superar la ambigüedad ideológica de Los lanzallamas y el revisionismo de los estudios sobre el peronismo, marcando la distancia entre Radek (Astier-Arlt) y Perón: “[...] conocí a un joven oficial del ejército que luego sería el omnipotente presidente de la nación [...] años después, yo fui víctima de la arbitrariedad y de la injusticia de su poder” (123).

El par dicotómico peronismo-fascismo/anarquismo-democracia queda confirmado en el siguiente capítulo, "El club de los soviéticos", que condensa su experiencia sindical en YPF, de mano de exiliados republicanos. Los personajes de esta sección exhiben un tono antifacista, anarquista y huelguista que se yuxtapone con referencias históricas relacionadas con la política de privatizaciones de los noventa. Esta contigüidad textual plantearía una continuidad lógica entre el anarquismo pasado y la crítica actual al neoliberalismo. Pero fundamentalmente cumple la función de ratificar la supuesta dimensión irracional del peronismo que ha sido promovida por la izquierda (127). La mención del año 1945 como el año de la derrota puntualiza entonces la oposición izquierda-democracia/peronismo-totalitarismo, pero además fortalece las dicotomías racional/irracional, civilizado/bárbaro.

El carácter definitorio de lo político en la identidad del personaje demuestra que la novela de Eckhardt plantea una reescritura del sistema de connotaciones del texto arltiano que reencauza, por la vía de la internalización de las normas hegemónicas, el carácter contradictorio de los personajes arltianos. La novela La nueva rabia exhibe así el ajuste ideológico-cultural a los patrones dominantes dentro del campo crítico,

\footnotetext{
Revista Iberoamericana, Vol. LXXVIII, Núm. 241, Octubre-Diciembre 2012, 895-911 ISSN 0034-9631 (Impreso)

ISSN 2154-4794 (Electrónico)
} 
cultural y literario argentino. Silvio Astier no sólo ha cambiado de nombre (Radeck), sino que en su experiencia vital no hay lugar para las tensiones de orden ideológico y cultural. Aprendió a escribir con el debido respeto a la tradición literaria argentina y a distanciarse del peronismo. Por el contrario, la novela de Silvestre, al presentar el mundo del trabajo desde una perspectiva de género, logra ampliar el sistema de connotaciones textuales y exponer una conciencia crítica. La dignificación del trabajo de la mujer no necesariamente se tradujo ni en la revisión de los papeles que le han sido asignados históricamente, ni de la predeterminación ideológica de éstos en la construcción de las subjetividades de género. Tampoco implicó una crítica de la mirada masculina sobre el trabajo de la mujer. A pesar de haber pasado de las fábricas a los comercios, a las oficinas y los estudios profesionales, el espacio laboral ha representado para la mujer un lugar de explotación e inseguridad que ratifica el papel protector de la educación formal. No sólo es el medio del ascenso social, sino también el del resguardo de la dignidad, puesto que el trabajo, sobre todo el no calificado, pondría en peligro la integridad de sus atributos de género.

De este modo, tanto a nivel semántico como a nivel formal ambas novelas figuran el trabajo dentro de un sistema de connotaciones que niega la crítica arltiana. Por lo tanto, podría decirse que ambas novelas reescriben el sistema de significación que Arlt criticó mediante la desfamiliarización y la inversión. Por un lado, esto reafirma su polisemia y su valor como modelo de escritura (Barthes, S/Z 10), y por el otro, confirma que el texto de Arlt condensa un problema central en la literatura argentina: el de las fisuras de un modelo cultural hegemónico y centralista, cimentado en una noción letrada de la cultura que además es antagónica al trabajo.

En este sentido, puede concluirse que la reescritura de El juguete rabioso en Si yo muero primero, de Susana Silvestre, y en La nueva rabia de Marcelo Eckhardt, no ratifica el comentario arltiano sobre el trabajo; pero, partiendo de su negación ambos textos articulan voces y contextos dialógicos que dan cuenta de las contradicciones existentes dentro y fuera del campo literario respecto de la relación entre trabajo y cultura. En este sentido, ambos textos se ajustan a un Bildungsroman específico de Hispanoamérica en el que la presencia de lo social y lo histórico permiten que en el texto no se borren las definiciones, los orígenes y las crisis de la cultura (Kushigian; Moretti). Los cambios de signo y desplazamientos operados en estas novelas ofrecen una perspectiva crítica de la forma en que el campo literario se ha configurado en torno de las representaciones sociales del trabajo. Por lo tanto, ambas novelas, ubicadas en los extremos de la serie literaria marcada por el retorno del realismo y por la preocupación por el tema laboral, ponen de manifiesto dos aspectos: en primer lugar, la centralidad del texto arltiano en la reflexión sobre el trabajo; y en segundo término, el surgimiento de nuevas series literarias (Chejfec, Pradelli, Jarkowski) cuyo eje es el tema de la dignidad desde la perspectiva de la relación entre trabajo, género y cultura.

\footnotetext{
(3) Revista Iberoamericana, Vol. LXXVIII, Núm. 241, Octubre-Diciembre 2012, 895-911 ISSN 0034-9631 (Impreso) ISSN 2154-4794 (Electrónico)
} 
Arlt, Roberto. El juguete rabioso. 1926. Obra completa. Tomo 1. Buenos Aires: Carlos Lohlé, 1981.

Armstrong, David. “Meaning in Work.” New Left Review I/10 (July-August 1961). 16-23. Avellaneda, Andrés. "Clase media y lectura: La construcción de los sentidos”. Roberto Arlt. Los siete locos. Los lanzallamas. Mario Goloboff, coord. Madrid: ALLCA XX, 2000. 633-656.

"Queremos tanto a Julio: decires políticos dela literatura argentina". Explicación de los textos literarios. Special Issue on Julio Cortázar and New Latin American Fiction XXXII/1 \& 2 (2003-2004): 62-71.

"Evita: cuerpo y cadáver de la literatura”. Evita:mitos y representaciones. Marysa Navarro, comp. Buenos Aires: Fondo de Cultura Económica, 2002.

"Construyendo el monstruo. Modelos y subversiones en los relatos (feministas) de aprendizaje”. Inti. Revista de crítica literaria latinoamericana 40-41 (19941995): 219-231.

"Realismo, Antirrealismo, Territorios Canónicos. Argentina Literaria Después de los Militares”. Fascismoy experiencia literaria: reflexiones parauna recanonización. Hernán Vidal, ed. Minnesota: Society for the Study of Contemporary Hispanic and Lusophone Revolutionay Literatures, 1985.

"Recordando con ira: Estrategias ideológicas y ficcionales argentinas a fin de siglo”. Revista Iberoamericana LXIX/202 (enero-marzo 2003): 119-135.

Bakhtin, M.M. Speech Genres and Other Late Essays. Austin: U of Texas P, 1986.

Barrancos, Dora. Educación, cultura y trabajadores (1890-1930). Buenos Aires: Centro Editor de América Latina, 1991.

Barthes, Roland. The Pleasure of the Text. Nueva York: Hill and Wang, 1975. S/Z. Paris: Éditions du Seuil, 1976.

Capdevila, Analía. "Las novelas de Arlt. Un realismo para la modernidad”. Historia crítica de la literatura argentina. El imperio realista. María Teresa Gramuglio, ed. Buenos Aires: Emecé Editores, 2002.

Castelnouvo, Elías y Lubrano Zas. Palabras con Elías Castelnuovo. Buenos Aires: Carlos Pez Editor, 1969.

Chejfec, Segio. Boca de lobo. Buenos Aires: Alfaguara, 2000.

Dalmaroni, Daniel. "Ni muerto has perdido tu nombre". Luis Gusman. Ni muerto has perdido tu nombre. Buenos Aires: Sudamericana, 2002.

Diego, José Luis de. "La novela de aprendizaje en Argentina”. Orbis Tertius III/6 (1998): 15-40.

Drucaroff, Elsa. "Entrevista a Elsa Drucaroff”. Sudor de tinta. Noviembre 2009. $<$ http://revistasudordetinta.blogspot.com/2009/11/entrevista-elsa-drucaroff.html> 4 octubre 2012.

\footnotetext{
Revista Iberoamericana, Vol. LXXVIII, Núm. 241, Octubre-Diciembre 2012, 895-911 ISSN 0034-9631 (Impreso) ISSN 2154-4794 (Electrónico)
} 
Eckhardt, Marcelo. La nueva rabia. Buenos Aires: Sudamericana, 2008.

Fogwill, Rodolfo. En otro orden de cosas. Barcelona: Mondadori, 2001.

Fontela, María de los Angeles. La novela de autoformación: una aproximación teórica e histórica al ‘Bildungsroman’ desde la narrativa española. Oviedo: Universidad de Oviedo, 1996.

Gamerro, Carlos. El secreto y las voces. Buenos Aires: Norma, 2002.

Gramsci, Antonio. Cultura y literatura. Barcelona: Ediciones Península, 1972.

Gusmán, Luis. Villa. Buenos Aires: Alfaguara, 1995.

Güiraldes, Ricardo. Don Segundo Sombra. Buenos Aires: Proa, 1926.

Iser, Wolfgang. The Act of Reading. A Theory of Aesthetic Response. Baltimore: John Hopkins UP, 1978.

Jakobson, Roman. “On Realism in Art”. Language in Literature. Cambridge: Harvard UP, 1987. 19-27

Jarkowski, Anibal. El trabajo. Buenos Aires: Editorial Tusquets, 2007.

Jauss, Hans. Toward an Aesthetic of Reception. Minneapolis: University of Minnesota, 1982.

Jitrik, Noé. "Entre el dinero y el ser. Lectura de El juguete rabioso, de Roberto Arlt”. La memoria compartida. 1976. Buenos Aires: Centro Editor de América Latina, 1987. 68-103.

Kohan, Martín. Dos veces junio. Buenos Aires: Sudamericana, 2002.

Kushigian, Julia A. Reconstructing Childhood. Strategies of Reading for Culture and Gender in the Spanish American Bildungsroman. Cranbury: Associated UP, 2003.

Lobato, Mirta Zaida. Historia de las trabajadoras en la Argentina. Buenos Aires: Edhasa, 2007.

Marx, Karl. El Capital. Tomo I -Vol. I. México: Siglo XXI, 1994.

Moretti, Franco. The Way of The World. The Bildungsroman in European Culture. Londres: Verso, 1987.

Pezzoni, Enrique. El texto y sus voces. Buenos Aires: Sudamericana, 1986.

Pradelli, Angela. Combi. Buenos Aires: Emecé, 2008.

Sábato, Hilda y Luis Alberto Romero. Los trabajadores de Buenos Aires. La experiencia del mercado: 1850-1880. Buenos Aires: Sudamericana, 1986.

Sarlo, Beatriz. El imperio de los sentimientos. Buenos Aires: Norma, 2004.

Secombe, Wally. “The Housewife and Her Labour under Capitalism”. New Left Review I/83 (January-February 1974): 3-24.

Silvestre, Susana. Si yo muero primero. Buenos Aires: Letra Buena, 1991.

Suriano, Juan. Anarquistas. Cultura y política libertaria en Buenos Aires (1890-1910). Buenos Aires: Manantial, 2001.

Vázquez, Karina. "Trabajo y literatura: el topos de la mujer obrera en la narrativa argentina del siglo XX”. El Interpretador 34 (Septiembre 2008). <http://www. elinterpretador.net/34KarinaElizabethVazquez-ElToposDeLaMujerObrera.html>.

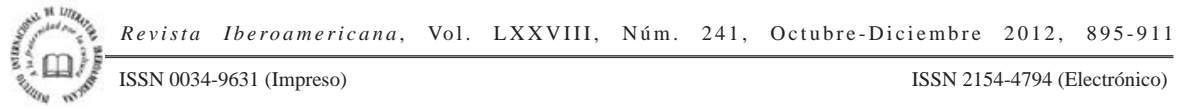


Vincent, David. The Rise of Mass Literacy. Reading and Writing in Modern Europe. Malden: Blackwell Publishers, 2000.

Revista Iberoamericana, Vol. LXXVIII, Núm. 241, Octubre-Diciembre 2012, 895-911 ISSN 2154-4794 (Electrónico) 
